\title{
Determination of Glimepiride in Rat Serum by RP-HPLC Method
}

\author{
Sujatha Samala, Sandhya Rani Tatipamula, Ciddi Veeresham \\ University College of Pharmaceutical Sciences, Kakatiya University, Warangal, India \\ E-mail: ciddiveeresham@yahoo.co.in \\ Received August 27, 2010; revised November 12, 2010; accepted November 17, 2010
}

\begin{abstract}
A simple and sensitive reverse phase high performance liquid chromatography (RP-HPLC) method was developed for the determination of glimepiride in rat serum. The assay involves one step liquid-liquid extraction with methanol. Gliclazide was used as an internal standard. Chromatographic separation was performed on a $\mathrm{C}_{18}$ column using a mobile phase of methanol: $10 \mathrm{mM}$ phosphate buffer (80:20 v/v) adjusted to $\mathrm{pH} 3.0$ with orthophosphoric acid, at a flow rate of $1.0 \mathrm{ml} / \mathrm{min}$ and UV detection at $230 \mathrm{~nm}$. The retention time of glimepiride and gliclazide was found to be 5.5 and $4.0 \mathrm{~min}$ and separation was complete in less than $10 \mathrm{~min}$. The method was validated for linearity, accuracy and precision were found to be acceptable over the range of $0.5-500 \mu \mathrm{g} / \mathrm{ml}$ for glimepiride. The method was found suitable to analyse rat serum samples for application in pharmacokinetic, pharmacodynamic, bioavailability/bioequivalence studies.
\end{abstract}

Keywords: Glimepiride, Gliclazide, RP-HPLC, Rat Serum

\section{Introduction}

The sulfonylurea glimepiride (1-[[p-[2-(3-ethyl-4-methy 1-2-oxo-3-pyrroline-1-carboxamido)ethyl]phenyl]sulfonyl]3-(trans-4-methylcyclohexyl) urea) used widely in the treatment of non-insulin dependent Type II diabetes mellitus $[1,2]$. It acts by stimulating insulin secretions from the beta cells of pancreas and is also known to increase peripheral insulin sensitivity thereby decreasing insulin resistance. It can be used in combination with metformin, thiazolidinediones, alpha-glucosidase inhibitors and insulin $[3,4]$. After oral administration, it is completely absorbed from the gastrointestinal tract. Peak plasma concentration is reached $2-3 \mathrm{~h}$ after dosing. Its bioavailability changes a little with food and glimepiride $(99.5 \%)$ are bound to proteins. Glimepiride is completely metabolised in liver [5]. The structures of glimepiride and gliclazide (internal standard IS) are shown in Figure 1.

To date there is no method was available for determination of glimepiride in rat serum, so an RP-HPLC method was developed for determination of glimepiride in rat serum. Several different methods have been reported for qualitative and quantitative analysis of glimepiride in human plasma and biological samples; these include micellar electrokinetic capillary chromatography (MECC) with diode-array detection (DAD) or ultraviolet
(UV) detection [6], high performance liquid chromatography (HPLC) with DAD [7] and UV detection [8] and derivative UV spectrophotometric detection [9], liquid chromatography-electrospray ionization mass spectrometry (LC-ESI/MS) [10-13], an HPLC method for the quantification of glimepiride in tablets [14], the determination of related substances in glimepiride [15], the quantification of cis-isomer of glimepiride by normal phase chromatography [16] and the quantification of cis-isomer of glimepiride in a bulk drug substance by

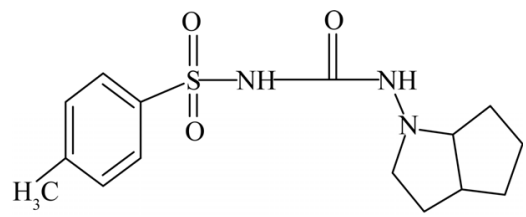

(a)

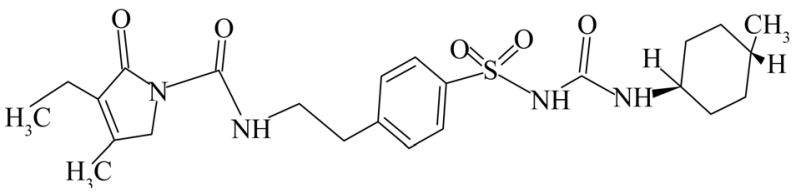

(b)

Figure 1. Chemical structures of (a) Gliclazide and (b) Glimepiride. 
reverse-phase chromatography [17] have been reported. However, these methods are not ideal for pharmacokinetics work, because they are time consuming owing to derivatization, arduous sample preparation and long chromatographic run times.

The main objective of this work was to develop a simple, rapid and sensitive RP-HPLC method for the determination of glimepiride in rat serum by liquid-liquid extraction. The developed and validated method is rapid, reproducible with simple mobile phase, sample preparation steps, improved sensitivity and a short chromatographic run time. The usability of this method can be explored further by the possibility of its application to a human pharmacokinetic study using similar chromatographic condition. The technique was validated, successfully applied to the pharmacokinetic study of glimepiride in rats after oral administration.

\section{Experimental}

\subsection{Chemicals}

Glimepiride and gliclazide (IS) were obtained from Dr. Reddy's laboratories (Hyderabad, India). Methanol of HPLC grade, Potassium dihydrogen orthophosphate and orthophosphoric acid of AR grade $(99.5 \%)$ were procured from Merck and Milli-Q water was used.

\subsection{Instrumentation and Chromatographic Conditions}

The HPLC system consisted of a Shimadzu LC-10AT pump, a Rheodyne 7725i sample injector with a $20 \mu \mathrm{l}$ loop and a Shimadzu SPD-M10Avp diode array detector. The data acquisition was performed by processing software "LC Solution" (Shimadzu Corp.). The method was developed on a LiChrosphere 100 RP 18 e $(125 \times 4.0 \mathrm{~mm}$ i.d, $5 \mu \mathrm{m})$ column maintained at ambient temperature.

The mobile phase was 80:20 (v/v) mixture of methanol and $10 \mathrm{mM}$ Potassium dihydrogen orthophosphate ( $\mathrm{pH}$ adjusted to 3.0 with orthophosphoric acid) delivered at a flow rate of $1 \mathrm{ml} / \mathrm{min}$. The column was maintained at $30^{\circ} \mathrm{C}$ and the detection was carried out at a wavelength of $230 \mathrm{~nm}$. The injection volume was $20 \mu \mathrm{L}$.

\subsection{Preparation of the Standard Solutions}

\subsubsection{Stock and Working Standard Solutions}

The stock solution of glimepiride $(1000 \mu \mathrm{g} / \mathrm{ml})$ was prepared by dissolving $25 \mathrm{mg}$ in $25 \mathrm{ml}$ methanol and further dilutions were prepared in methanol to obtain working standards in a concentration range of 0.1 $500 \mu \mathrm{g} / \mathrm{ml}$.

\subsubsection{Internal Standard (IS)}

For IS stock solution $10 \mathrm{mg}$ of gliclazide was weighed and dissolved in $10 \mathrm{ml}$ of methanol. The stock solution was again diluted with methanol to working solution of gliclazide which was at $25 \mu \mathrm{g} / \mathrm{ml}$. All solutions were stored at $-20^{\circ} \mathrm{C}$.

\subsubsection{Sample Preparation}

Serum samples were stored at $-20^{\circ} \mathrm{C}$ and allowed to thaw at room temperature before processing. In brief, to $100 \mu \mathrm{L}$ serum, $100 \mu \mathrm{L}$ aliquot of working standard solution of glimepiride was added in a polypropylene centrifuge tubes; $100 \mu \mathrm{L}$ aliquot of gliclazide solution $(25 \mu \mathrm{g} / \mathrm{ml})$ was added as an IS and the tube was shaken for $1 \mathrm{~min}$. To this, $100 \mu \mathrm{L}$ of methanol was added for precipitation and the tubes were vortexed each for $1 \mathrm{~min}$. Then all the tubes were centrifuged for $20 \mathrm{~min}$ at $3000 \mathrm{rpm}$. Clear supernatant was collected in another centrifuge tubes and a $20 \mu \mathrm{L}$ aliquot was injected into the analytical column.

\subsubsection{Application of the Assay}

The method described above was applied to the pharmacokinetic studies of glimepiride in rats. Sprague-Dawley rats $(200-250 \mathrm{~g})$ were housed with free access to food and water. The rats were fasted overnight with free access to water before administration of drug. After a single oral administration of $1 \mathrm{mg} / \mathrm{kg}$ of glimepiride, $0.5 \mathrm{ml}$ of blood samples were collected from retro orbital plexus sinus at $0.5,1,2,4,6,8,12$ and $24 \mathrm{~h}$ time-points. Serum was separated by centrifugation and stored at $-20^{\circ} \mathrm{C}$ until analysis. Aliquots of $0.1 \mathrm{ml}$ serum samples were processed and analyzed for glimepiride concentrations.

The pharmacokinetic parameters were calculated with a Non-Compartmental model using Kinetica TM Software (version 4.4.1 Thermo Electron Corporation, U.S.A). Each value is expressed as Mean \pm SD.

\section{Results and Discussion}

\subsection{Method Validation}

\subsubsection{Selectivity and Specificity}

Blank serum was tested for endogenous interference. A representative chromatogram of the serum blank is shown in Figure 2(a). No additional peaks of endogenous substances were observed. Figure 2(b) shows the chromatograms of calibration standard containing $30 \mu \mathrm{g} / \mathrm{ml}$ of glimepiride and $25 \mu \mathrm{g} / \mathrm{ml}$ of gliclazide in serum. Typical chromatogram of serum samples which were collected $1 \mathrm{~h}$ after oral administration of $1 \mathrm{mg} / \mathrm{kg}$ of glimepiride to a rat is shown in Figure 2(c). The observed retention times are 4.0 and $5.5 \mathrm{~min}$ for gliclazide and glimepiride, respectively. 


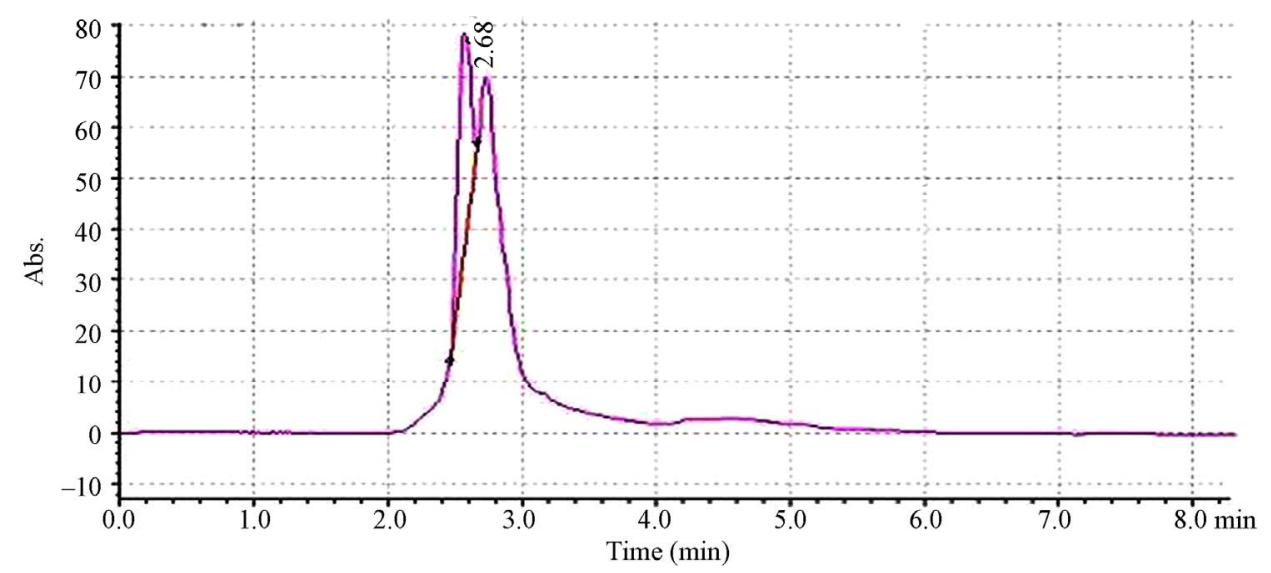

(a)

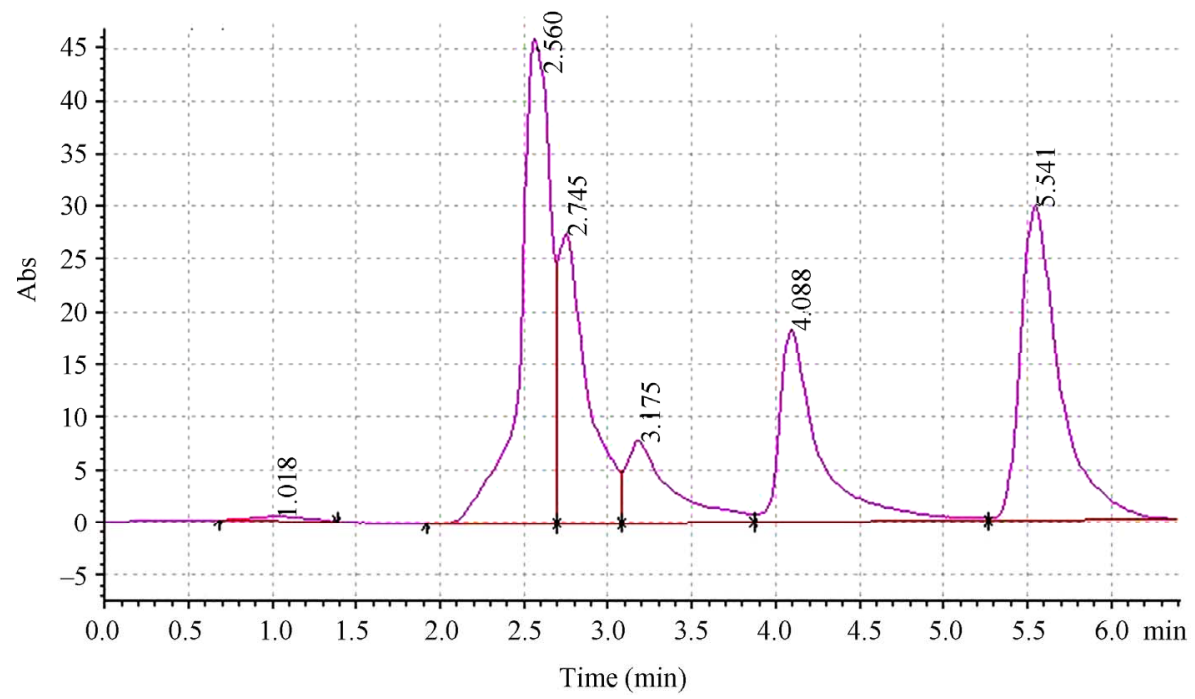

(b)

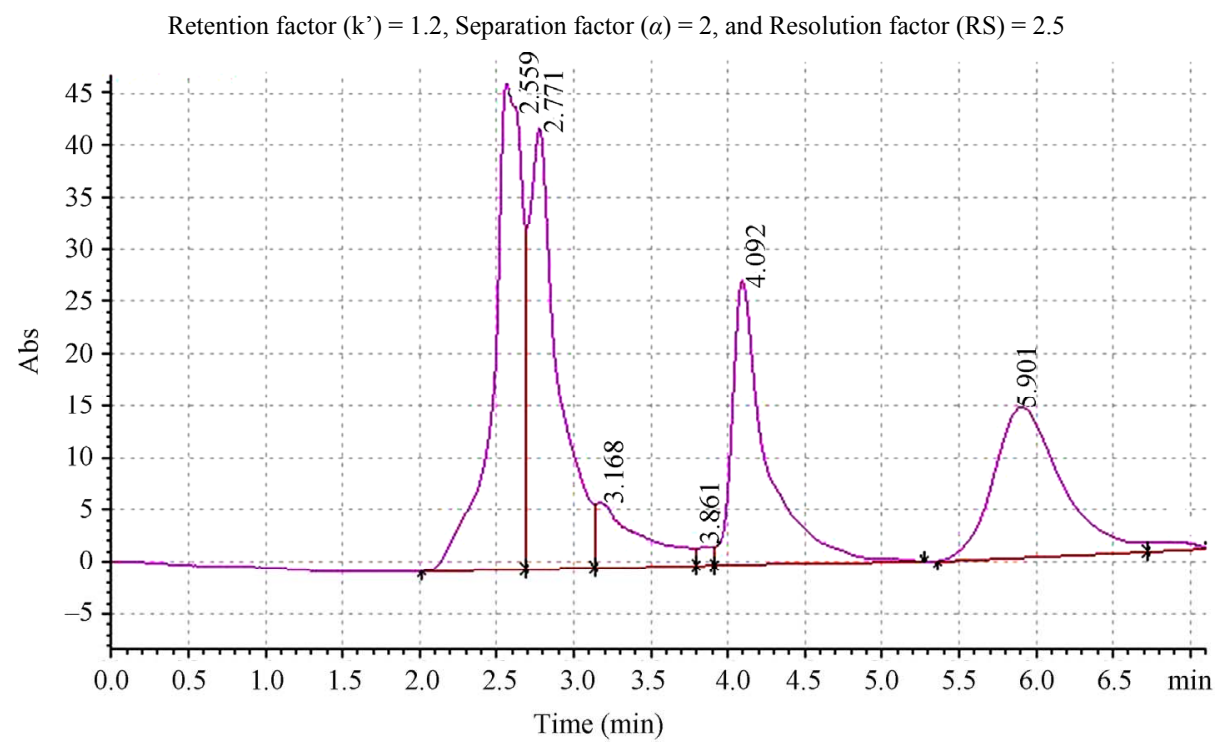

(c)

Figure 2. HPLC trace of glimepride and gliclazide (IS) using Ultraviolet detection at $230 \mathrm{~nm}$. (a) Blank serum sample; (b)

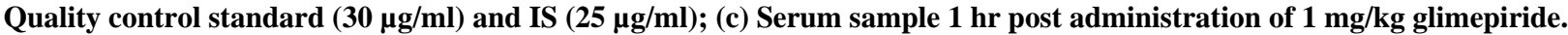




\subsubsection{Linearity and Limit of Quantitation}

Linear calibration curves with correlation coefficients greater than 0.9999 were obtained over the concentration range $0.5-100 \mu \mathrm{g} / \mathrm{ml}$ for glimepiride in rat serum. The typical equation of the calibration curve is as follows; $Y=0.0686 x+0.0192, r=0.9999$. The results shown that within the concentration range indicated there was an excellent correlation between peak area ratio and each concentration of glimepiride.

The limit of quantitation, defined as the lowest concentration analyzed with an accuracy of $\pm 15 \%$ and a coefficient of variation $<15 \%$, was $0.5 \mu \mathrm{g} / \mathrm{ml}$ for the determination of glimepiride in serum.

\subsubsection{Precision and Accuracy}

Precision and accuracy of the assay were determined, using replicate analyses $(n=6)$ of quality control samples at three concentrations, by performing the complete analytical runs on the same day and also on three consecutive days. The data obtained for glimepiride were within the acceptable limits to meet the guidelines for bioanalytical methods. The results are depicted in Table 1.

\subsubsection{Extraction Recovery}

Extraction recovery of glimepiride was determined by comparing peak areas obtained from extracted serum samples with those found by extracting blank matrices through the extraction procedure and spiking with a known amount of glimepiride. The results showed that the mean extraction recoveries of glimepiride were $>85 \%$ at concentrations of $1.0,5.0$, and $10.0 \mu \mathrm{g} / \mathrm{ml}$ respectively (Table 2). Different organic extraction solvents were evaluated in the experiment, including Methanol, Ethylacetate, Acetonitrile, Dichloromethane, Chloroform and Diethylether. Methanol proved to be the most efficient in extracting glimepiride from rat serum and had a small variation in extraction recoveries over the concentration range.

\subsubsection{Stability}

The amount of glimepiride recovered over a period of 30 days in serum samples stored at $-20^{\circ} \mathrm{C}$ did not differ from the initial concentrations, which were shown in Table 3.

\subsection{Application of the Analytical Method in Pharmacokinetic Studies}

The described method was applied to a pharmacokinetic study in rats. After a single oral administration of glimepiride $(1 \mathrm{mg} / \mathrm{kg})$ to rats, serum concentrations were determined over a period of $24 \mathrm{~h}$ after administration. The mean serum concentration-time curve after an oral dose of $1 \mathrm{mg} / \mathrm{kg}$ glimepiride is shown in Figure 3 and the main pharmacokinetic parameters are summarized in Table 4. The $\mathrm{C}_{\max }$ of glimepiride detected in the rats was $17.56 \mu \mathrm{g} / \mathrm{ml}$, and the $\mathrm{T}_{\max }$ was $4 \mathrm{hrs}$.

Table 1. Inter-day and Intra-day accuracy and precision for the analysis of Glimepiride in rat serum.

\begin{tabular}{|c|c|c|c|c|c|c|}
\hline \multirow{2}{*}{$\begin{array}{l}\text { Nominal concentration } \\
\qquad(\mu \mathrm{g} / \mathrm{ml})\end{array}$} & \multicolumn{3}{|c|}{ Inter-day } & \multicolumn{3}{|c|}{ Intra-day } \\
\hline & $\begin{array}{l}\text { Calculated concentration } \\
\text { Mean }(\mu \mathrm{g} / \mathrm{ml})^{\mathbf{a}} \pm \mathrm{SD}\end{array}$ & $\begin{array}{l}\text { Accuracy } \\
(\%)^{\mathbf{b}}\end{array}$ & $\begin{array}{l}\text { Precision } \\
(\% \text { RSD })^{\mathrm{c}}\end{array}$ & $\begin{array}{l}\text { Calculated concentration } \\
\text { Mean }(\mu \mathrm{g} / \mathrm{ml})^{\mathbf{a}} \pm \mathrm{SD}\end{array}$ & $\begin{array}{l}\text { Accuracy } \\
(\%)^{\mathbf{b}}\end{array}$ & $\begin{array}{l}\text { Precision } \\
(\% \text { RSD })^{\circ}\end{array}$ \\
\hline 1 & $1.045 \pm 0.02$ & 104.5 & 1.91 & $1.02 \pm 0.1$ & 102.1 & 9.79 \\
\hline 5 & $5.01 \pm 0.1$ & 100.2 & 2.00 & $4.92 \pm 0.25$ & 98.4 & 5.08 \\
\hline 10 & $10.08 \pm 0.52$ & 100.8 & 5.16 & $10.01 \pm 1.05$ & 100.1 & 10.5 \\
\hline
\end{tabular}

a: Averaged for six measurements at each concentration level $(\mathrm{n}=6)$; b: Accuracy $=($ mean observed concentration $)(\text { spiked concentration })^{-1} \times 100$; $\mathrm{c}$ Precision $(\% R S D)=(S D \times 100)(\text { mean observed concentration })^{-1}$.

Table 2. The percent extraction recovery of measurement of glimepiride in rat serum.

\begin{tabular}{cc}
\hline $\begin{array}{c}\text { Nominal concentration } \\
(\mu \mathrm{g} / \mathrm{ml})\end{array}$ & \% Recovery $^{\text {a,b }}$ \\
\hline 1 & 91.2 \\
5 & 86.4 \\
10 & 89.7 \\
\hline
\end{tabular}

a: Averaged for six measurements at each concentration level $(\mathrm{n}=6)$; $\mathrm{b}: \%$ recovery $=($ response of extracted spike) $($ response of post-extracted spike $)^{-1} \times 100$.
Table 3. Glimepiride stability results: Blank rat serum was spiked with 3 different concentrations of glimepiride and stored at $-20^{\circ} \mathrm{C}$ over a period of 30 days.

\begin{tabular}{ccccc}
\hline \multirow{2}{*}{$\begin{array}{c}\text { Concentration added } \\
(\mu \mathrm{g} / \mathrm{ml})\end{array}$} & \multicolumn{4}{c}{ Concentration obtained $(\mu \mathrm{g} / \mathrm{ml})$} \\
\cline { 2 - 5 } & Day 1 & Day 14 & Day 21 & Day 30 \\
\hline 1 & 1.02 & 0.98 & 1.05 & 1.002 \\
5 & 4.92 & 5.01 & 4.98 & 5.05 \\
10 & 10.01 & 10.12 & 9.98 & 9.99 \\
\hline
\end{tabular}




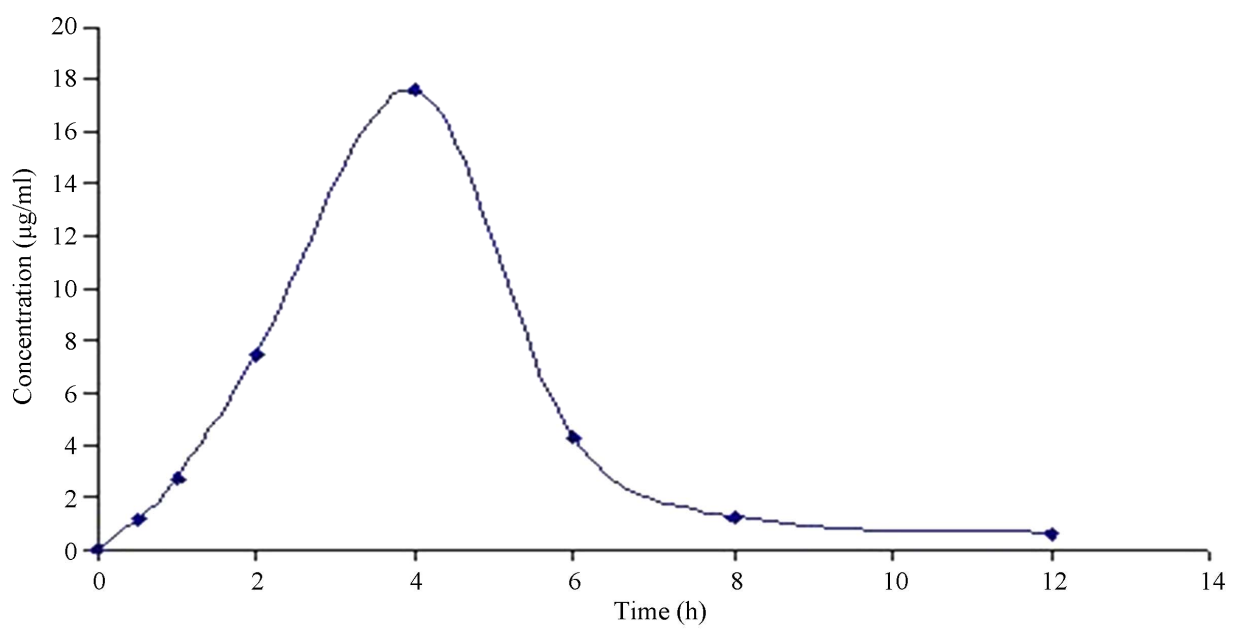

Figure 3. Mean serum concentration-time profile of glimepiride after oral administration of $1 \mathrm{mg} / \mathrm{kg}$ glimepiride in rats.

Table 4. The main pharmacokinetic parameters of mean drug serum concentration time curve (mean \pm SD, $n=6)$ of glimepiride in rats after single oral administration at $1 \mathrm{mg} / \mathrm{kg}$.

\begin{tabular}{ccccccc}
\hline & $\mathrm{C}_{\max }(\mu \mathrm{g} / \mathrm{ml})$ & $\mathrm{T}_{\max }(\mathrm{hrs})$ & $\mathrm{AUC}_{\text {o-n }}(\mu \mathrm{g} . \mathrm{h} / \mathrm{ml})$ & $\mathrm{AUC}_{\text {tot }}(\mu \mathrm{g} . \mathrm{h} / \mathrm{ml})$ & $\mathrm{t}_{1 / 2}(\mathrm{hrs})$ & $\mathrm{MRT}(\mathrm{hrs})$ \\
\hline Glimepiride & $17.56 \pm 0.3$ & $4.0 \pm 1.2$ & $55.6 \pm 1.4$ & $57.5 \pm 5.3$ & $1.05 \pm 0.8$ & $4.14 \pm 2.6$ \\
\hline
\end{tabular}

\section{Conclusion}

A sensitive and selective reverse phase HPLC method was developed for the pharmacokinetic study of glimepiride in rats. This analytical procedure is inexpensive and simple because it requires fewer preparation steps, is less time consuming than methods using pre-column derivatization, and is particularly suitable when tandem mass spectrometric detection is not available. The assay has been validated and the results have shown that the method is sensitive, accurate and reproducible. As a result, the proposed method is found to be appropriate and suitable for the determination of glimepiride in serum samples for pharmacokinetic, bioavailability or bioequivalence studies.

\section{Acknowledgements}

The authors are thankful to Dr. Reddy's laboratories, Hyderabad, India for the gift samples of glimepiride and gliclazide.

\section{References}

[1] A. L. McCall, "Clinical Review of Glimepiride," Expert Opinion on Pharmacotherapy, Vol. 2, No. 4, 2001, pp. 699-713. doi:10.1517/14656566.2.4.699

[2] J. Rosenstock, E. Samols, D. B. Muchmore and J. Schneider, "Glimepiride, a New Once-Daily Sulfonylurea: A
Double-Blind Placebo-Controlled Study Of NIDDM Patients," Diabetes Care, Vol. 19, No. 11, 1996, pp. 1194-1199. doi:10.2337/diacare.19.11.1194

[3] S. N. Davis, "The Role of Glimepiride in the Effective Management of Type 2 Diabetes," Journal of Diabetes and its Complications, Vol. 18, No. 6, 2004, pp. 367-376. doi:10.1016/j.jdiacomp.2004.07.001

[4] D. S. Bell, "Practical Considerations and Guidelines for Dosing Sulfonylureas in Monotherapy or Combination Therapy," Clinical Therapeutics, Vol. 26, No. 11, 2004, pp. 1714-1727. doi:10.1016/j.clinthera.2004.10.014

[5] M. Badian, A. Korn, K. H. Lehr, V. Malerczyk and W. Waldhausl, "Determination of the Absolute Bioavailability of Glimepiride (HOE 490), a New Sulfonylurea," International Journal of Clinical Pharmacology, Therapy and Toxicology, Vol. 30, No. 11, 1992, pp. 481-482.

[6] M. E. Roche, R. P. Oda, G. M. Lawson and J. P. Landers, "Capillary Electrophoretic Detection of Metabolites in the Urine of Patients Receiving Hypoglycemic Drug Therapy," Electrophoresis, Vol. 18, No. 10, 1997, pp. 1865-1874. doi:10.1002/elps.1150181024

[7] J. N. Jingar, S. J. Rajput, B. Dasandi and S. Rathnam, "Development and Validation of LC-UV for Simultaneous Estimation of Rosiglitazone and Glimepiride in $\mathrm{Hu}$ man Plasma," Chromatographia, Vol. 67, No. 11-12, 2008, pp. 951-955. doi:10.1365/s10337-008-0633-3

[8] Y. K. Song, J. E. Maeng, H. R. Hwang, J. S. Park, B. C. Kim, J. K. Kim and C. K. Kim, "Determination of Glimepiride in Human Plasma Using Semi-Microbore High-Performance Liquid Chromatography with Columnswitching," Journal of Chromatography B: Analytical Tech- 
nologies in the Biomedical and Life Sciences, Vol. 810, No. 1, 2004, pp. 143-149.

[9] I. U. Khan, F. Aslam, M. Ashfaq and M. N. Asghar, "Determination of Glimepiride in Pharmaceutical Formulations Using High-Performance Liquid Chromatography and First-Derivative Spectrophotometric Methods," Journal of Analytical Chemistry, Vol. 64, No. 2, 2009, pp. 171-175. doi:10.1134/S1061934809020130

[10] I. I. Salem, J. Idrees and J. I. Al Tamimi, "Determination of Glimepiride in Human Plasma by Liquid Chromatography-Electrospray Ionization Tandem Mass Spectrometry," Journal of Chromatography B: Analytical Technologies in the Biomedical and Life Sciences, Vol. 799, No. 1, 2004, pp. 103-109. doi:10.1016/j.jchromb.2003.10.024

[11] H. Kim, K. Y. Chang, H. J. Lee and S. B. Han, "Determination of Glimepiride in Human Plasma by Liquid Chromatography_Electrospray Ionization Tandem Mass Spectrometry," Bulletin of the Korean Chemical Society, Vol. 25, No. 1, 2004, pp. 109-114. doi:10.5012/bkcs.2004.25.1.109

[12] H. Kim, K. Y. Chang, C. H. Park, M. S. Jang, J. A. Lee, H. J. Lee and K. R. Lee, "Determination of Glimepiride in Human Plasma by LC-MS-MS and Comparison of Sample Preparation Methods for Glimepiride," Chromatographia, Vol. 60, No. 1-2, 2004, pp. 93-98. doi:10.1365/s10337-004-0351-4

[13] N .Yuzuak, T. Ozden, S. Eren and S. Ozilhan, "Determination of Glimepiride in Human Plasma by LC-MS-MS," Chromatographia, Vol. 66, No. 1, 2007, pp. 165-168. doi:10.1365/s10337-007-0368-6

[14] S. P. Pawar, G. A. Meshram and M. U. Phadke, "Simultaneous LC Estimation of Glimepiride and Metformin in Glimepiride Immediate Release and Metformin Sustained Release Tablets," Chromatographia, Vol. 68, No. 11-12, 2008, pp. 1063-1066. doi:10.1365/s10337-008-0802-4

[15] K. H. Lehr and P. Damm, "Simultaneous Determination of the Sulphonylurea Glimepiride and Its Metabolites in Human Serum and Urine by High-Performance Liquid Chromatography after Pre-Column Derivatization," Journal of Chromatography-Biomedical Applications, Vol. 526, No. 1, 1990, pp. 497-505. doi:10.1016/S0378-4347(00)82531-1

[16] The United States Pharmacopeia (USP) and the National Formulary (NF), "The Official Compendia of Standards," Vol. 29, No. 2, 2006, p. 1001.

[17] D. B. Pathare, A. S. Jadhav and M. S. Shingare, "RP-LC Determination of the Cis-Isomer of Glimepiride in a Bulk Drug Substance," Chromatographia, Vol. 66, No. 7-8, 2007, pp. 639-641. doi:10.1365/s10337-007-0356-X 